\title{
Flex-learning - Online or face to face - Learners' freedom of choice
}

\author{
Sangita Sukumaran
}

Professor and Head, Department of Pharmacology and Secretary, Bioethics Unit, Terna Medical College, Navi Mumbai, Maharashtra, India.

Corresponding Author: Sangita Sukumaran

E-mail: drsangi@gmail.com

\begin{abstract}
Bioethics education requires interactive methods in the teaching process. With the advances in internet and communication technology, students are able to gather more information than before. It is important to change teaching learning strategies from traditional face to face to include online learning. Flex learning is a thoughtful integration of classroom face-to-face learning experiences with online learning experiences. It is a student-centered approach with the teacher as the designer and facilitator of learning. Students will actively "experience" their learning, rather than being passive learners. Flexible learning gives students some choice in their learning format. They get to decide whether they want to approach lessons or even entire courses in face-to-face, online, or blended classrooms. Flexible learning gives students choices about when, where, and how they learn. The learning material is primarily delivered online to students prior to a face to face classroom session. Learning is self-guided as students independently learn and practice new concepts in a digital environment. Teachers are in the room to provide on-site support as needed. When technology is integrated into bioethics lessons, learners are more likely to be interested in and focused about the subjects they are studying. Advantages of flex learning are students learn critical thinking skills, collaborating with others, solving complex problems, developing different forms of communication and leadership- all aspects of learning unsupported by traditional, didactic lecturer driven approaches.
\end{abstract}

Key words: flexible learning, online learning, blended learning

\section{INTRODUCTION}

Bioethics education faces lot of challenges with respect to pedagogical advancements in higher education and the changing learning needs of the medical students. This has stressed the need for newer teaching and learning strategies, resources and learning environment on the part of both the students and teachers. With the advances in internet and communication technology, students are able to gather more information than before. It is important to change teaching learning strategies from traditional face to face to include online learning.

Flex learning is a thoughtful integration of classroom face-to-face learning experiences with online learning experiences. It is a student-centred approach with the teacher as the designer and facilitator of learning. Students will actively "experience" their learning, rather than being passive learners. According to Shurville and others, "Flexible Learning is a set of educational philosophies and systems, concerned with providing learners with increased choice, convenience, and personalisation to suit the learner [1]. 
With Flex learning, students have the choice of taking a class completely online, completely faceto-face in the classroom, or a combination of the two (blended learning) and they can switch back and forth between the formats without penalty or disadvantage. Flex learning shifts more of the control and responsibility to the students. This gives them the freedom to explore different learning environments and figure out what works best for them. The learning material is primarily delivered online to students prior to a face to face classroom session. Learning is self-guided as students independently learn and practice new concepts in a digital environment. Teachers are in the room to provide on-site support as needed. When technology is integrated into bioethics lessons, learners are more likely to be interested in and focused about the subjects they are studying. Advantages of flex learning are students learn critical thinking skills, collaborating with others, solving complex problems, developing different forms of communication and leadership- all aspects of learning unsupported by traditional, didactic lecturer driven approaches [2].

Flex learning helps to respond to flexibility and convenience wants of adult learners, accommodate increased number of learners in and outside classroom, address budget constraints in education funding and promote self-reliance and life-long learning [3].

And along the way, this discretion helps learners develop their abilities to self-evaluate and monitor their progress. The major hallmark of this learning transition is from teacher centred to learner focus paradigm.

\section{Characteristics of Flex learning [4]}

1. Reduction in traditional Face to Face time in learning environment

2. Offers flexibility in choice of delivery mode for learning

3. Offers equivalence in learning despite delivery mode

4. Offers convenience of fitting learning into personal schedule

5. Designed for student-centered and collaborative learning

6. Requires self-regulation and motivation for learning

7. Relies on technology in meeting learning outcomes to include assessment

The model, focus, role of the learner and technology has been changed drastically from traditional instruction to online learning environment as depicted in Table 1.

Table 1: Changes in Teaching Learning Environment

\begin{tabular}{|l|l|l|l|}
\hline \multicolumn{5}{|c|}{ Changes in Teaching Learning Environment } \\
\hline Model & Focus & Role of Learner & Technology \\
\hline $\begin{array}{l}\text { Traditional Face to } \\
\text { Face }\end{array}$ & Teacher & Passive & Chalk and Board \\
\hline Flex Learning & Learner & Active & Personal Computer \\
\hline
\end{tabular}

\section{Learning Theories applicable to Flexible learning environment}

1. Connectivism [5]: In connectivism learning, a teacher will guide students to information and answer key questions as needed, in order to support students learning and sharing on their own. Students are also encouraged to seek out information on their own online and express what they find.

2. Constructivism [3]: The student constructs knowledge from integrating new knowledge with past knowledge and experience.

3. Engagement [6]: This theory based on motivation and the idea that when students find the lesson meaningful and have a high level of interest in the tasks, they learn more effectively, tend to retain the information and are able to transfer it to other contexts. Students are engaged in collaborative learning and problem solving.

\section{Preparing for Flex learning Class in Bioethics}

Teaching ethical reasoning online presents its own particular challenges. Learning how to reason ethically is a dialectical, back-and-forth process. Simply delivering content through lectures and 
readings are at best supplementary forms of instruction. The primary form of instruction needs to be interactive because students need to present ideas, get feedback on those ideas, and then try out re-formed ideas that themselves will be subject to further modification. So, because learning ethical reasoning requires active, not passive learning [7] particular care must be given to ensuring that online study materials are designed with opportunities for rich interaction between students as well as between students and instructors.

The facilitator needs an understanding of the best uses of various offline and online technologies as well as face to face teaching, and the tasks that will help to support, so that he/she can design for an appropriate mix of these elements. For each activity the facilitator identifies as anchor, content, application, future use, or some combination of these [8]. An anchor activity is designed to connect the material to participants' previous work or life experiences. Content activities, as the term implies, provide substantive learning material that may include research, data, theories and the like, and may be presented through charts, lists, stories, readings, lectures or other similar activities. Application activities present an opportunity for participants to work with the content during the course of training to reinforce the acquisition of their new skills or knowledge. And finally, future use information relates the content to the work the learner will do once they begin taking cases.

\section{Role of Learners, Instructors and institutions in Flex learning}

Learners, instructors, and institutions all have a role to play in flexible learning. Learners must take responsibility for their own learning, taking advantage of opportunities that are presented to them and being able to self-advocate for the delivery method that serves their learning best. Instructors must be able to identify opportunities for flexible learning, "with a growing emphasis on managing the learning process rather than being the primary provider of learning material." Institutions must build flexible systems that provide students with choices in their learning, as well as maintaining the frameworks that ensure a quality learning experience [9].

\section{How is flexible learning implemented?}

Implementing flexible learning will require teachers to make choices in a range of areas [10].

1. Modes of delivery of material and interaction: Developing a curriculum will require teachers to make selections related to resources and how they might be delivered to the learners.

2. Structure and content: Choices will have to be made about the program content and how that content would be structured.

3. Pace: An appropriate pace of learning would have to be considered that is not overwhelming to the learner.

4. Contact and interactions between learners and teacher and among learners: The alternatives available to conduct the interaction between learners and learners as well as learners and teachers would have to be considered and structured into the program.

5. Type and mix of media used: Teachers will have to draw from a selection of media options that suit the structure, content, interactions and learner needs.

6. Extent of self-direction of learners: Teachers would have to make decisions on the degree to which they allow learners to be autonomous and direct their learning.

7. Constraints: There are always constraints on time, space, access to learning resources and experiences and these realities will moderate the choices and levels of flexibility. It also gives rise to a number of student support, staff and resources issues including staff development and HR issues.

\section{Methods for effective flex learning}

The following face-to-face interactions and technology mediated interactions may be considered for effective flex learning -

1. Certain contexts of the topic could be covered by using videos and power point presentations. 
2. Group discussions: Certain identified areas of the content can serve as topics for group discussion which will help learners in better understanding of the chosen content.

3. Quiz: A short quiz with limited questions from identified contents can be conducted by providing immediate feedback which will improve the learners' focused attention.

4. Expert address: A video call is now very much possible with the help of smart phones. With due appointment, an expert in the respective field may be asked to address the learners with some novel information about the topic by calling him/her over a smart phone. The speech can be projected to the whole class for listening.

5. Using laptops in the classroom: If lap tops are available with learners and the classroom has internet connectivity (possibly with wifi) important websites of respective subject can be suggested for the learners to browse and reflect on the topic in different views. This can also be done by the facilitator him/herself using an interactive board (smart board).

6. Collaborative learning: An online collaborative writing of assignment or a discussion may be mooted out with the help of online tools such as Google docs.

7. Peer to peer presentations: Flex learning can also be extended to the next session through different ways. One of the way is by using Peer to peer presentations. In this, learners will be required to present a ten-minute topic of their own in groups of 4 or 5 to their peers. They should be encouraged to choose topics they felt had not been covered sufficiently in the classroom.

\section{Advantages of flex learning}

1. It can keep students focused for longer periods of time. The use of computers to look up information/data is a tremendous time saver, especially when used to access a comprehensive resource like the Internet to conduct research. This time-saving aspect can keep students focused on a project much longer than they would with books and paper resources, and it helps them develop better learning through exploration and research.

2. It makes students more excited to learn. When technology is integrated into school lessons, learners are more likely to be interested in, focused on, and excited about the subjects they are studying. Subjects that might be monotonous can be much more engaging with virtual lessons, tutoring, and the streaming of educational videos.

3. It enables students to learn at their own pace. With the integration of technology, students are able to get direct, individualized instruction from the computer. This form of supplemental teaching allows them to engage with the information at times that are most convenient for them and helps them become more self-directed in the learning process. It also gives the teacher more time to accomplish classroom objectives, while freeing them up to help the students who need more help.

4. It prepares students for the future: Students will learn the critical thinking and workplace skills they will need to be successful in their futures. Education is no longer just about learning and memorizing facts and figures; it's about collaborating with others, solving complex problems, developing different forms of communication and leadership skills [11].

5. Flex learning in Bioethics education can be useful when teaching communication skills. For example communicating to a patient or his relatives about a medical error that has occured. In such scenarios the teacher can share with students videos on how the communication is done to disclose the medical error. The students can then be evaluated through role plays to test their understanding.

\section{Challenges of Flex learning}

1. Flexible learning may not be effective for complex content when compared to simpler content [12].

2. Learners with low motivation or bad study habits may fall behind

3. Without the routine structures of a traditional class, students may get lost or confused about course activities and deadlines

4. Students may feel isolated from the instructor and classmates 
5. Instructor may not always be available when students are studying or need help

6. Slow Internet connections or older computers may make accessing course materials frustrating

7. Managing computer files and online learning software can sometimes seem complex for students with beginner-level computer skills

8. Hands-on or lab work is difficult to simulate in a virtual classroom

\section{CONCLUSIONS}

Flexible Learning is a set of educational philosophies and systems, concerned with providing learners with increased choice, convenience, and personalisation to suit the learner. It provides learners with choices about where, when, and how learning occurs. The central goal of flex learning is learner empowerment through self-directed learning. Flex learning uses technology to improve quality of education and promote life-long learning. However, flex learning is contextdependent and it is challenging for it demands proper knowledge, attitude and skills on the part of facilitators with respect to teaching techniques and technologies. A successful implementation of flexible learning in one domain may not necessarily have value within another domain [13]. Although flexible learning makes use of computers and the internet, it should be remembered that the focus should not be on the technology. Rather, the educator must first determine the best way to teach a particular topic and then determine how technology might enhance the teaching. In future, flex learning will be an innovative teaching learning strategy in bioethics education.

\section{REFERENCES}

1. Shurville S, O'Grady T, Mayall P. Educational and institutional flexibility of Australian Educational Software. Campus-Wide Information Systems, Emerald Group Publishing Limited 2008;25(2):7484.

2. Majumdar S. Network based flexible learning: Prospects and challenges in the 21st Century: Invited keynote address at the International Conference of Vocational Education and Training (IVETA '97), Helsinki, Finland. August 24-28; 1997.

3. Ling P, Fraser K. The future of learning and teaching in next generation spaces. International Perspectives on Higher Education 2014;12:65-84

4. Cybinski P, Selvanathan S. Learning experience and learning effectiveness in undergraduate statistics: Modelling performance in traditional and flexible learning environments. Journal of Innovative Education 2009;3(2):251-71.

5. Siemens G. Connectivism: A learning theory for the digital age. International Journal of Instructional Technology and Distance Learning 2014;2(1:3-10.

6. Marshall S. Engagement theory, WebCT, and academic writing in Australia. International Journal of Education and Development using Information and Communication Technology (IJEDICT) 2007;3(2):109-15.

7. Sternberg RJ. We need to teach for ethical conduct. The Educational Forum 2009; 73(3):190-8.

8. Flex-learning edition. for children Available on http://nc.casaforchildren.org/files/secure/community/programs/Training/FlexLearning_2012/F acilitator_Manual_Session_0_2012.pdf

9. Ryan A, Tilbury D. Flexible Pedagogies: New Pedagogical Ideas. Higher Education Academy, York ; 2013.

10. Deakin University, Australia (2009). Introducing flexible learning. Consultado el 08 de Mayo del 2013. http://www.deakin.edu.au

11. Huneycutt T. Technology in the classroom: The benefits of blended learning. Retrieved from http://www.nms.org/blog/TabId/58/PostId/188/technology-in-the- classroom-the-benefits-ofblended-learning.aspx ; 2013.

12. Granger BP. Enhancing Training Outcomes in the Context of e-Learning: The Impact of Objective Learner Control, Training Content Complexity, Cognitive Load, Learning Goal Orientation, and Metacognitive Strategies. Graduate School Theses and Dissertations ; 2012.

13. Zayapragassarazan Z, Kumar S. Blended Learning in Medical Education. NTTC Bulletin 2012;19(2):4-5. 